\title{
Growth and Development of the HIV Exposed Uninfected Children below 5 Years in Developing Countries: Focus on Nutritional Challenges, Mortality and Neurocognitive Function
}

\author{
Patience Kuona1, Gwendoline Kandawasvika1, Felicity Gumbo¹, Kusum Nathoo1, \\ Babill Stray-Pedersen ${ }^{2,3}$ \\ ${ }^{1}$ Department of Paediatrics and Child Health, College of Health Sciences, University of Zimbabwe, \\ Harare, Zimbabwe \\ ${ }^{2}$ Division of Women and Children, Oslo University Hospital, Rikshospitalet, Oslo, Norway \\ ${ }^{3}$ Institute of Clinical Medicine, University of Oslo, Oslo, Norway \\ Email: patiekuona@gmail.com
}

Received 3 August 2014; revised 2 September 2014; accepted 16 September 2014

Copyright (C) 2014 by authors and Scientific Research Publishing Inc.

This work is licensed under the Creative Commons Attribution International License (CC BY).

http://creativecommons.org/licenses/by/4.0/

c) (i) Open Access

\begin{abstract}
The future of any population is children. Resource limited settings with a high prevalence of HIV infection notably also have an excessive burden of malnutrition. The advances in prevention of mother to child HIV transmission programmes have led to very effective combination antiretroviral regimens resulting in growing numbers of HIV exposed but uninfected children. The mortality of HIV exposed but uninfected children below 5 years is high in resource limited settings. It is also important to pay particular attention to their longitudinal growth and neurodevelopmental outcomes. In these settings, the contribution of feeding practices, choice of complementary foods and micronutrient deficiencies, to health outcomes of HIV exposed uninfected children are not clearly defined. This review highlights some gaps in research that need to be addressed in areas with increasing numbers of HIV exposed but uninfected children. Interventions to reduce mortality, improve growth and neurodevelopmental outcomes in HIV exposed uninfected children from resource limited areas should be prioritized.
\end{abstract}

\section{Keywords}

HIV Exposed Uninfected, Under-Nutrition, Neurocognitive, Mortality, Micronutrients 


\section{Introduction}

Resource limited settings with a high prevalence of human immunodeficiency virus (HIV) infection notably also have an excessive burden of under-nutrition resulting from reduced food intake and repeated infectious diseases [1] [2]. The advances in mother-to-child prevention of HIV transmission (PMTCT) programmes have led to very effective combination antiretroviral regimens resulting in growing numbers of HIV exposed but uninfected (HEU) children in these settings. Most of these children reside in Sub-Saharan Africa as almost 90\% of HIV infected individuals live in this region [2]. Research has clearly shown that HIV infected children experience poor growth [3] [4], poor neurocognitive outcomes [5] and have higher mortality [6] compared to HIV unexposed uninfected children. In the developed countries it seems that the growth of HEU children is similar to that of HIV unexposed children [7]. However, there is limited research regarding nutritional, neurocognitive and mortality outcomes in the HEU children residing in resource limited settings especially Sub-Saharan Africa [3]. Undernutrition is a major contributor to under-five mortality globally. Underweight trends are increasing in Sub-Saharan Africa with figures estimated to reach 43 million by 2015 [1]. Of the world's under five children, 165 million were reported as stunted whilst 8 million had wasting in 2012 [8]. Under five mortality is highest in Sub-Saharan Africa and Southern Asia. Nearly half the world's under five deaths were concentrated in Sub-Saharan Africa in 2012 with 98 deaths per 1000 [9]. The leading causes of death in children below 5 years excluding neonatal deaths are pneumonia and diarrhoea. Under-nutrition and HIV/AIDS are important under lying factors in most of these deaths in Sub-Saharan Africa. HIV exposed children who are uninfected also suffer from an increased burden of under-nutrition [10], neurocognitive dysfunction [11] as well as high mortality [12] making it essential for researchers in resource limited areas to pay attention to their health outcomes. This review highlights some gaps in research that need to be addressed in areas with increasing numbers of HEU children to improve their quality of life.

\section{Growth and HIV Exposed Uninfected Children}

The hallmark of under-nutrition is growth failure. In low income communities under-nutrition results from multiple factors including suboptimal infant feeding practices, poor quality of complementary foods, frequent infections and micronutrient deficiencies [13]. High levels of stunting, wasting and underweight have been reported in the postnatal period in children from areas with increased burden of HIV infection. Under-nutrition occurs more frequently in HIV infected children [4] [14]-[16] but it has also been noted to occur in HIV exposed but uninfected children [10]. Some researchers in resource limited settings have reported early occurrence of undernutrition before age three months in both HIV infected and HIV exposed uninfected children [17] while other researchers have reported later occurrence of under-nutrition after six months of age [18]. Maternal HIV infection is associated with underweight [19] in HIV exposed uninfected children. Multiple factors have been associated with occurrence of under-nutrition in children during the postnatal period. These include socio-demographic, environmental and immunological factors [15] [17]-[20] in settings with a high burden of HIV infection. Infant and young child feeding controversies in the context of HIV infection in resource limited areas have negatively affected the growth and developmental outcomes of HIV exposed uninfected children. Early weaning has been associated with poor growth and stunting [10] [21] [22]. In addition, exposure to antiretroviral drugs in utero has been associated with reduced birth weights [23]-[25] in HIV exposed uninfected children in some studies but does not seem to impair postnatal growth in these children [25] [26]. Early growth of HIV exposed uninfected children may be slower than unexposed children and this may be associated with primiparity, low maternal weight gain during pregnancy and subclinical mastitis [27] in resource limited settings. However, in the developed world these children demonstrate accelerated postnatal growth velocity [7] and catch up growth between 1 and 2 years of age [28]. Children residing in HIV affected households have been reported to have an increased prevalence of stunting [29] which represent chronic malnutrition probably due to poor food security in the household and increased exposure to opportunistic infections [30]. Under-nutrition is associated with several micronutrient deficiencies [31] [32] including iron, zinc and selenium deficiency. Poor micronutrient intake has been documented in HIV exposed uninfected children weaned early at 6 months in resource limited settings [33]. Research has shown that supplementation of these micronutrients is beneficial in all children [34]-[39]. Hence, identification and treatment of micronutrient deficiencies is important.

\section{Nutrition and Neurodevelopment in Children}

Children living in resource limited setting are vulnerable to poor neurodevelopmental outcomes [13]. Causes in- 
clude under-nutrition, infectious disease such as HIV, cerebral malaria, tuberculosis, low birth weight, birth trauma, genetic disorders and poverty [13]. Under-nutrition is prevalent resulting in irreversible physical and neurological damage. Studies suggest that stunting and wasting mediate the effect of environmental risk and neurodevelopmental outcome in children living in resource constrained settings [40] [41]. Of note, under-nutrition in women of child bearing age, especially pregnant women, predisposes to low birth weight which further increases the risk for neuro-disability and mortality [42].

\subsection{Micronutrients and Cognitive Development}

Micronutrient deficiencies such as iron, iodine, zinc, selenium and n-3 fatty acids also affect central nervous system development through various patho-physiological mechanisms. Iron is an essential nutrient for all body tissues and is present in the brain of the developing fetus, where it is needed for proper formation of neural tissue [43] and development of brain cells [44]. Iron deficiency, a common form of nutritional deficiency, results from long-term imbalance caused by an inadequate dietary iron intake; poor iron absorption or utilization; increased iron requirements for growth during childhood or chronic blood losses. In the later stages of iron depletion, the haemoglobin concentration decreases, resulting in iron deficiency anaemia [45].

\subsection{HIV and Neurodevelopment}

Sub-Saharan Africa has the highest burden of children infected with HIV infection [46] as shown in Figure 1 [47]. Information on the effect of HIV infection on neurodevelopment among children living in developing countries is limited due to under reporting. The relationship between HIV infection and neurodevelopmental outcomes in infancy is determined by maternal and infant host factors both of which also influence HIV disease onset and severity. HIV encephalopathy, as characterized by the deterioration of cognitive, motor and behavioral function has been described in infants as young as three months of age [48]. Early in the HIV epidemic, arrested progressive HIV encephalopathy was associated with residual neurological and cognitive impairment [49]. The risk for neurodevelopmental impairment was higher among infants infected with HIV at the age 3 months in a study of infants enrolled in a prevention of mother-to-child transmission of HIV programme [50]. It is envisaged that with the uptake of World Health Organization (WHO) HIV paediatric combined antiretroviral guidelines [51], where all infants are started on therapy regardless of disease stage, few children will manifest motor or cognitive deficits as a result of HIV infection. In countries with high adult HIV prevalence, up to $30 \%$ of infants may be HIV exposed uninfected, but the effect of maternal HIV on the child's neurodevelopment remains unknown. Of note, is the lack of information on the cognitive outcome of African children exposed to, but uninfected with HIV [52]. The number of this sub-population of children is anticipated to rise as availability of more efficacious antiretroviral therapy for PMTCT programmes becomes more available. A review of studies from 2000-2010 suggested HIV-infected and HIV-exposed-uninfected children in resource-poor settings demonstrate greater neurodevelopmental delay compared with HIV-unexposed children [11]. Emphasis should be placed on the counseling of pregnant mothers to participate in PMTCT services. In resource limited areas, the promotion

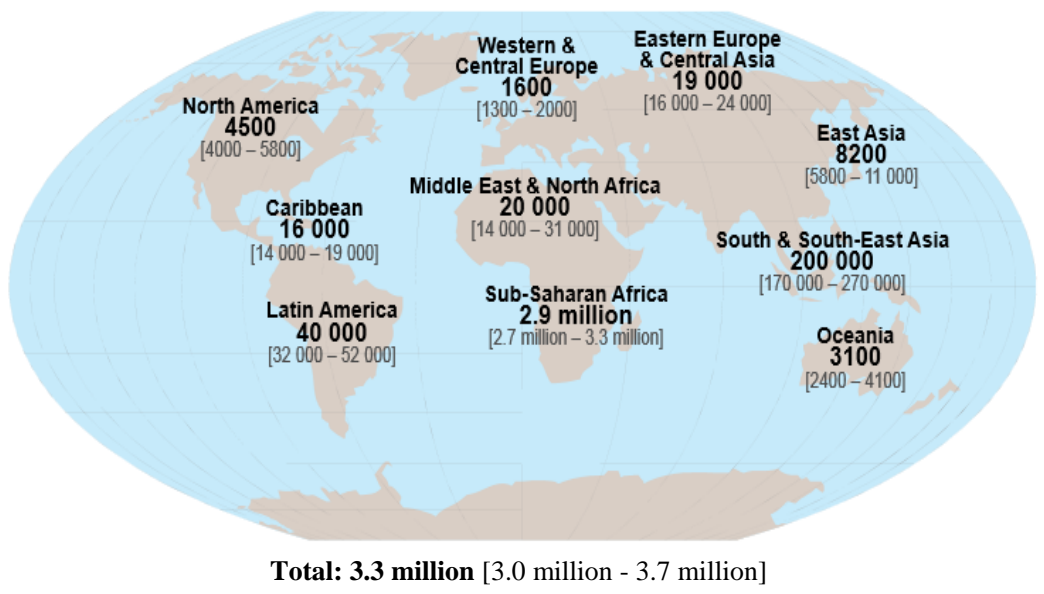

Figure 1. Estimated number of children below 15 years living with HIV 2012. 
of early infant diagnosis and treatment should be emphasized as knowing the HIV exposure status of the child is necessary for monitoring growth and neurodevelopment.

\section{Nutritional Challenges and Mortality in HIV Exposed Uninfected Children}

Global determinants of under-five mortality are national income and water/sanitation facilities [53]. Policies initiated in many countries addressing these issues have resulted in a decline in the under 5 mortality rates [54]. However, in areas of high HIV prevalence improvement of gross domestic product have not resulted in a clear decline of under-five mortality particularly in sub Saharan Africa. HIV/AIDS is associated with nutritional deficiencies in infected children and poor nutrition affects disease progression and reduces survival of HIV infected people [4]. HIV exposed children who are uninfected also suffer from high mortality [55]-[57]. Several factors have been suggested including feeding patterns, opportunistic infections and immune deficiencies [58].

\subsection{Severe Acute Malnutrition and Mortality}

Severe acute malnutrition (SAM) in children is defined anthropometrically by the WHO as weight for height -3SD below the mean, or a mid-upper arm circumference of less than $11.5 \mathrm{~cm}$ in children aged 6 months to 5 years old [50]. The clinical presentation of SAM includes severe wasting (marasmus), nutritional oedema (Kwashiorkor), or a mixed picture [59]. Complicated SAM is associated with biochemical abnormalities, micronutrient deficiencies, and concurrent infections which lead to a high mortality. In-patient care and hospitalization is recommended by the WHO for the management of the severe acutely malnourished child with complications including hypothermia, hypoglycaemia, electrolyte imbalance, micronutrient deficiencies, diarrhoea and severe bacterial infections. In Zambia in 2009, 430 children aged 6 to 59 months with complicated SAM admitted to a tertiary hospital were followed up. The majority of the children presented with diarrhoea (67.3\%) and $40 \%$ died. The median length of stay was 9 days. Children with diarrhoea on admission had two and half times higher odds of mortality than those without diarrhoea [60]. This brings out the challenges faced by resource limited settings where the burden of SAM is high and resources to reduce mortality from SAM are scarce.

\subsection{The HIV Infected Child with SAM}

In a prospective cohort in Tanzania, HIV infected children less than 15 years initiating antiretroviral therapy were examined. Compared with children with weight for age $\mathrm{Z}$ score (WAZ) $>-1$ those with WAZ $<-2$ to -3 had a nearly double risk of death, and among those with $\mathrm{WAZ}<-3$ the risk more than tripled. Other baseline risk factors were severe anaemia, severe immune suppression, living in the poorest district and opportunistic infections including Tuberculosis [61]. The effect of antiretroviral therapy on nutritional rehabilitation of children with SAM is not well documented. Metabolic complications of antiretroviral therapy include lipodystrophy, dyslipidaemia, lactic acidosis, insulin resistance and osteopenia. These maybe compounded by SAM [62]. Considering immune reconstitution, in the ARROW trial, 3.2\% of 1207 African children initiated on antiretroviral therapy were hospitalized for SAM within 12 weeks of treatment initiation. Mortality was $32 \%$ in marasmic patients and 20\% in kwashiorkor all with CD4 and WAZ scores less than -3 SD [63]. The mechanism of this form of illness is not clear.

\subsection{The HIV Exposed Uninfected Child}

Concern comes from minimizing HIV infection while promoting optimum growth. A safe and effective feeding regimen improves child survival. Cessation of breast feeding has been implicated in increased infant mortality, especially from diarrhoea [64]. Malnutrition in HIV exposed uninfected children can come from infections, food insecurity in HIV affected households and barriers to accessing health. Malnutrition is a risk factor of acquisition of primary TB infection [65]. In addition, tuberculosis results in wasting and poor appetite. In the BAN trial HIV exposed uninfected children had increased morbidity post weaning after 24 weeks namely pneumonia, febrile illness, diarrhoea, growth faltering and malaria. Introduction of prophylactic cotrimoxazole was associated with reduced rates of morbidity and mortality in the BAN trial [12]. In the setting of maternal micronutrient management, supplementation of HIV exposed infants with vitamin B, C and E does not reduce mortality [66]. More research is required in terms of nutrition in anti-retroviral therapy exposed infants. 


\section{Conclusion}

As we reduce the paediatric HIV burden in resource limited countries with effective PMTCT regimens, it is important to look into method that optimizes growth, neurodevelopment and reduces mortality in HIV exposed uninfected children. Research to determine the important determinants of growth, neurodevelopment and mortality in HEU children from resource poor settings should be prioritized and cost effective interventions applied to improve their health outcomes.

\section{Acknowledgements}

This work was supported by a grant from the Letten Foundation.

\section{References}

[1] de Onis, M., et al. (2004) Estimates of Global Prevalence of Childhood Underweight in 1990 and 2015. JAMA, 291, 2600-2606. http://dx.doi.org/10.1001/jama.291.21.2600

[2] UNAIDS (2012) Global Report: UNAIDS Report on the Global AIDS Epidemic: 2012.

[3] Isanaka, S., Duggan, C. and Fawzi, W.W. (2009) Patterns of Postnatal Growth in HIV-Infected and HIV-Exposed Children. Nutrition Reviews, 67, 343-359. http://dx.doi.org/10.1111/j.1753-4887.2009.00207.x

[4] Kimani-Murage, E.W., et al. (2011) Nutritional Status and HIV in Rural South African Children. BMC Pediatrics, 11, 23. http://dx.doi.org/10.1186/1471-2431-11-23

[5] Le Doare, K., Bland, R. and Newell, M.L. (2012) Neurodevelopment in Children Born to HIV-Infected Mothers by Infection and Treatment Status. Pediatrics, 130, e1326-e1344. http://dx.doi.org/10.1542/peds.2012-0405

[6] Chilongozi, D., et al. (2008) Morbidity and Mortality among a Cohort of Human Immunodeficiency Virus Type 1-Infected and Uninfected Pregnant Women and Their Infants from Malawi, Zambia, and Tanzania. Pediatric Infectious Disease Journal, 27, 808-814. http://dx.doi.org/10.1097/INF.0b013e31817109a4

[7] Neri, D., et al. (2013) Growth and Body Composition of Uninfected Children Exposed to Human Immunodeficiency Virus: Comparison with a Contemporary Cohort and United States National Standards. Journal of Pediatrics, 163, 249-254. http://dx.doi.org/10.1016/j.jpeds.2012.12.034

[8] UNICEF (2012) Committing to Child Survival: A Promise Renewed-Progress Report 2012. United Nations Children's Fund, New York.

[9] UNICEF (2013) UN Inter Agency Group for Child Mortality Estimation 2013. Levels and Trends in Child Mortality.

[10] McGrath, C.J., et al. (2012) The Prevalence of Stunting Is High in HIV-1-Exposed Uninfected Infants in Kenya. Journal of Nutrition, 142, 757-763. http://dx.doi.org/10.3945/jn.111.148874

[11] Le Doaré, K., Bland, R. and Newell, M.L. (2012) Neurodevelopment in Children Born to HIV-Infected Mothers by Infection and Treatment Status. Pediatrics, 130, e1326-e1344. http://dx.doi.org/10.1542/peds.2012-0405

[12] Kourtis, A.P., Wiener, J., Kayira, D., Chasela, C., Ellington, S.R., Hyde, L., Hosseinipour, M., van der Horst, C. and Jamieson, D.J. (2013) Health Outcomes of HIV-Exposed Uninfected African Infants. AIDS, 27, 749-759. http://dx.doi.org/10.1097/QAD.0b013e32835ca29f

[13] Olness, K. (2003) Effects on Brain Development Leading to Cognitive Impairment: A Worldwide Epidemic. Journal of Developmental \& Behavioral Pediatrics, 24, 120-130. http://dx.doi.org/10.1097/00004703-200304000-00009

[14] Bailey, R.C., Kamenga, M.C., Nsuami, M.J., Nieburg, P. and St Louis, M.E. (1999) Growth of Children According to Maternal and Child HIV, Immunological and Disease Characteristics: A Prospective Cohort Study in Kinshasa, Democratic Republic of Congo. International Journal of Epidemiology, 28, 532-540. http://dx.doi.org/10.1093/ije/28.3.532

[15] Venkatesh, K.K., Lurie, M.N., Triche, E.W., De Bruyn, G., Harwell, J.I., McGarvey, S.T. and Gray, G.E. (2010) Growth of Infants Born to HIV-Infected Women in South Africa According to Maternal and Infant Characteristics. Tropical Medicine \& International Health, 15, 1364-1374. http://dx.doi.org/10.1111/j.1365-3156.2010.02634.X

[16] Fausto, M.A., Carneiro, M., Antunes, C.M.F., Colosimo, E.A. and Pinto, J.A. (2011) Longitudinal Anthropometric Assessment of Infants Born to HIV-1-Infected Mothers, Belo Horizonte, Southeastern Brazil. Revista de Saúde Pública, 45, 652-660. http://dx.doi.org/10.1590/S0034-89102011005000040

[17] Ram, M., Gupte, N., Nayak, U., Kinikar, A.A., Khandave, M., Shankar, A.V., et al. (2012) Growth Patterns among HIV-Exposed Infants Receiving Nevirapine Prophylaxis in Pune, India. BMC Infectious Diseases, 12, 282. http://dx.doi.org/10.1186/1471-2334-12-282

[18] Mcdonald, C.M., Kupka, R., Manji, K.P., Okuma, J., Bosch, R.J., Aboud, S., Kisenge, R., Spiegelman, D., Fawzi, W.W. and Duggan, C.P. (2012) Predictors of Stunting, Wasting and Underweight among Tanzanian Children Born to 
HIV-Infected Women. European Journal of Clinical Nutrition, 66, 1265-1276. http://dx.doi.org/10.1038/ejcn.2012.136

[19] Muhangi, L., Lulea, S.A., Mpairwea, H., Ndibazzaa, J., Kizzaa, M., Nampijja, M., et al. (2013) Maternal HIV Infection and Other Factors Associated with Growth Outcomes of HIV-Uninfected Infants in Entebbe, Uganda. Public Health Nutrition, 16, 1548-1557. http://dx.doi.org/10.1017/S1368980013000499

[20] Thorne, C.J., Roberts, L.M., Edwards, D.R., Haque, M.S., Cumbassa, A. and Last, A.R. (2013) Anaemia and Malnutrition in Children Aged 0-59 Months on the Bijagos Archipelago, Guinea-Bissau, West Africa: A Cross-Sectional, Population-Based Study. Paediatrics and International Child Health, 33, 151-160. http://dx.doi.org/10.1179/2046905513Y.0000000060

[21] Patel, D., Bland, R., Coovadia, H., Rollins, N., Coutsoudis, A. and Newell, M.L. (2010) Breastfeeding, HIV Status and Weights in South African Children: A Comparison of HIV-Exposed and Unexposed Children. AIDS, 24, 437-445. http://dx.doi.org/10.1097/QAD.0b013e3283345f91

[22] Arpadi, S., Fawzy, A., Aldrovandi, G.M., Kankasa, C., Sinkala, M., Mwiya, M., Thea, D.M. and Kuhn, L. (2009) Growth Faltering Due to Breastfeeding Cessation in Uninfected Children Born to HIV-Infected Mothers in Zambia. American Journal of Clinical Nutrition, 90, 344-353. http://dx.doi.org/10.3945/ajcn.2009.27745

[23] Powis, K.M., Smeaton, L., Ogwu, A., Lockman, S., Dryden-Peterson, S., van Widenfelt, E., Leidner, J., Makhema, J., Essex, M. and Shapiro, R.L. (2011) Effects of in Utero Antiretroviral Exposure on Longitudinal Growth of HIV-Exposed Uninfected Infants in Botswana. JAIDS Journal of Acquired Immune Deficiency Syndromes, 56, 131-138. http://dx.doi.org/10.1097/QAI.0b013e3181ffa4f5

[24] Briand, N., Le Coeur, S., Traisathit, P., Karnchanamayul, V., Hansudewechakul, R., Ngampiyasakul, C., et al. (2006) Growth of Human Immunodeficiency Virus-Uninfected Children Exposed to Perinatal Zidovudine for the Prevention of Mother-to-Child Human Immunodeficiency Virus Transmission. Pediatric Infectious Disease Journal, 25, 325-332. http://dx.doi.org/10.1097/01.inf.0000207398.10466.0d

[25] Gibb, D.M., Kizito, H., Russell, E.C., Chidziva, E., Zalwango, E., Nalumenya, R., et al. (2012) Pregnancy and Infant Outcomes among HIV-Infected Women Taking Long-Term ART with and without Tenofovir in the DART Trial. PLoS Medicine, 9, e1001217. http://dx.doi.org/10.1371/journal.pmed.1001217

[26] Vigano, A., Mora, S., Giacomet, V., Stucchi, S., Manfredini, V., Gabiano, C., et al. (2011) In Utero Exposure to Tenofovir Disoproxil Fumarate Does Not Impair Growth and Bone Health in HIV-Uninfected Children Born to HIVInfected Mothers. Antiviral Therapy, 16, 1259-1266. http://dx.doi.org/10.3851/IMP1909

[27] Makasa, M., Kasonka, L., Chisenga, M., Sinkala, M., Chintu, C., Tomkins, A. and Filteau, S. (2007) Early Growth of Infants of HIV-Infected and Uninfected Zambian Women. Tropical Medicine \& International Health, 12, 594-602. http://dx.doi.org/10.1111/j.1365-3156.2007.01836.x

[28] Ibieta, M.F., Bellón Cano, J.M., Ramos Amador, J.T., González-Tomé, M.I., Guillén Martín, S., Navarro Gómez, M., et al. (2009) Growth of Uninfected Infants Exposed to Antiretrovirals Born to HIV-Infected Woman. Anales de Pediatría, 71, 299-309. http://dx.doi.org/10.1016/j.anpedi.2009.06.019

[29] Ndirangu, M., Wariero, J.O., Sachs, S.E., Masibo, P. and Deckelbaum, R.J. (2011) Nutritional Status of Under-Five Children in HIV-Affected Households in Western Kenya. Food and Nutrition Bulletin, 32, 159-167.

[30] Gompels, U.A., Larke, N., Sanz-Ramos, M., Bates, M., Musonda, K., Manno, D., Siame, J., Monze, M. and Filteau, S., The CIGNIS Study Group (2012) Human Cytomegalovirus Infant Infection Adversely Affects Growth and Development in Maternally HIV-Exposed and Unexposed Infants in Zambia. Clinical Infectious Diseases, 54, 434-442. http://dx.doi.org/10.1093/cid/cir837

[31] Ejaz, M.S. and Latif, N. (2010) Stunting and Micronutrient Deficiencies in Malnourished Children. Journal of Pakistan Medical Association, 60, 543-547.

[32] Hettiarachchi, M. and Liyanage, C. (2012) Coexisting Micronutrient Deficiencies among Sri Lankan Pre-School Children: A Community-Based Study. Maternal \& Child Nutrition, 8, 259-266. http://dx.doi.org/10.1111/j.1740-8709.2010.00290.x

[33] Parker, M.E., Tembo, M., Adair, L., Chasela, C., Piwoz, E.G., Jamieson, D.J., et al. (2013) The Health of HIVExposed Children after Early Weaning. Maternal \& Child Nutrition, 9, 217-232. http://dx.doi.org/10.1111/j.1740-8709.2011.00369.x

[34] Best, C., Neufingerl, N., Del Rosso, J.M., Transler, C., van den Briel, T. and Osendarp, S. (2011) Can Multi-Micronutrient Food Fortification Improve the Micronutrient Status, Growth, Health, and Cognition of Schoolchildren? A Systematic Review. Nutrition Reviews, 69, 186-204. http://dx.doi.org/10.1111/j.1753-4887.2011.00378.x

[35] Chhagan, M.K., Van den Broeck, J., Luabeya, K.K.A., Mpontshane, N., Tomkins, A. and Bennish, M.L. (2010) Effect on Longitudinal Growth and Anemia of Zinc or Multiple Micronutrients Added to Vitamin A: A Randomized Controlled Trial in Children Aged 6-24 Months. BMC Public Health, 10, 145. http://dx.doi.org/10.1186/1471-2458-10-145

[36] Hieu, N.T., Sandalinasa, F., de Sesmaisonsa, A., Lailloua, A., Tama, N.P., Khan, N.C., et al. (2012) Multi-Micronutrient- 
Fortified Biscuits Decreased the Prevalence of Anaemia and Improved Iron Status, Whereas Weekly Iron Supplementation Only Improved Iron Status in Vietnamese School Children. British Journal of Nutrition, 108, 1419-1427. http://dx.doi.org/10.1017/S0007114511006945

[37] Jack, S.J., Ou, K., Chea, M., Chhin, L., Devenish, R., Dunbar, M., et al. (2012) Effect of Micronutrient Sprinkles on Reducing Anemia: A Cluster-Randomized Effectiveness Trial. JAMA Pediatrics, 166, 842-850. http://dx.doi.org/10.1001/archpediatrics.2012.1003

[38] Kounnavong, S., Sunahara, T., Mascie-Taylor, C.G.N., Hashizume, M., Okumura, J., Moj, K., Boupha, B. and Yamamoto, T. (2011) Effect of Daily versus Weekly Home Fortification with Multiple Micronutrient Powder on Haemoglobin Concentration of Young Children in a Rural Area, Lao People’s Democratic Republic: A Randomised Trial. Nutrition Journal, 10, 129. http://dx.doi.org/10.1186/1475-2891-10-129

[39] Suchdev, P.S., Ruth, L.J., Woodruff, B.A., Mbakaya, C., Mandava, U., Flores-Ayala, R., Jefferds, M.E.D. and Quick, R. (2012) Selling Sprinkles Micronutrient Powder Reduces Anemia, Iron Deficiency, and Vitamin a Deficiency in Young Children in Western Kenya: A Cluster-Randomized Controlled Trial. American Journal of Clinical Nutrition, 95, 1223-1230. http://dx.doi.org/10.3945/ajcn.111.030072

[40] Abubakar, A., Van de Vijver, F., Van Baar, A., Mbonani, L., Kalu, R., Newton, C. and Holding, P. (2008) Socioeconomic Status, Anthropometric Status, and Psychomotor Development of Kenyan Children from Resource-Limited Settings: A Path-Analytic Study. Early Human Development, 84, 613-621. http://dx.doi.org/10.1016/j.earlhumdev.2008.02.003

[41] Bradley, R.H. and Corwyn, R.F. (2002) Socioeconomic Status and Child Development. Annual Review of Psychology, 53, 371-399. http://dx.doi.org/10.1146/annurev.psych.53.100901.135233

[42] Lartey, A. (2008) Maternal and Child Nutrition in Sub-Saharan Africa: Challenges and Interventions. Proceedings of the Nutrition Society, 67, 105-108. http://dx.doi.org/10.1017/S0029665108006083

[43] Iannotti, L.L., Tielsch, J.M., Black, M.M. and Black, R.E. (2006) Iron Supplementation in Early Childhood: Health Benefits and Risks. American Journal of Clinical Nutrition, 84, 1261-1276.

[44] Lozoff, B., Beard, J., Connor, J., Felt, B., Georgieff, M. and Schallert, T. (2006) Long-Lasting Neural and Behavioral Effects of Iron Deficiency in Infancy. Nutrition Reviews, 64, S34-S43. http://dx.doi.org/10.1301/nr.2006.may.S34-S43

[45] De-Regil, L.M., Jefferds, M.E., Sylvetsky, A.C. and Dowswell, T. (2011) Intermittent Iron Supplementation for Improving Nutrition and Development in Children under 12 Years of Age. Cochrane Database of Systematic Reviews, 2011, Article ID: CD009085.

[46] Bakamjian, L., et al. (2013) Global Report: UNAIDS Report on the Global AIDS Epidemic 2013. Journal of the American Board of Family Medicine, 26, 187-195.

[47] UNAIDS (2013) Global Regional Epidemiology Slides. Http://Www.Unaids.Org/En/Media/Unaids/Contentassets/Documents/Epidemiology/2013/Gr2013/201309 Epi Core En.Pdf

[48] Tardieu, M., Le Chenadec, J., Persoz, A., Meyer, L., Blanche, S. and Mayaux, M.J. (2000) HIV-1-Related Encephalopathy in Infants Compared with Children and Adults. Neurology, 54, 1089-1095. http://dx.doi.org/10.1212/WNL.54.5.1089

[49] Chiribo, C., Fleishman, S., Champion, S., Gaye-Robinson, E. and Abrams, E. (2009) The Incidence and Prevalence of HIV Encephalopathy in Children with HIV Infection Receiving Highly Active Anti Retroviarl Therapy (HAART). Journal of Pediatrics, 146, 402-407. http://dx.doi.org/10.1016/j.jpeds.2004.10.021

[50] Kandawasvika, G.Q., Ogundipe, E., Gumbo, F.Z., Kurewa, E.N., Mapingure, M.P. and Stray-Pedersen, B. (2011) Neurodevelopmental Impairment among Infants Born to Mothers Infected with Human Immunodeficiency Virus and Uninfected Mothers from Three Peri-Urban Primary Care Clinics in Harare, Zimbabwe. Developmental Medicine \& Child Neurology, 53, 1046-1052. http://dx.doi.org/10.1111/j.1469-8749.2011.04126.x

[51] WHO (2013) Consolidated Guidelines on the Use of Antiretroviral Drugs for Treating and Preventing HIV Infection: Recommendations for a Public Health Approach. World Health Organization, Geneva.

[52] Filteau, S. (2009) The HIV-Exposed, Uninfected African Child. Tropical Medicine \& International Health, 14, 276287. http://dx.doi.org/10.1111/j.1365-3156.2009.02220.x

[53] Hanf, M., Nacher, M., Guihenneuc, C., Tubert-Bitter, P. and Chavance, M. (2013) Global Determinants of Mortality in under 5s: 10 Year Worldwide Longitudinal Study. British Medical Journal, 347, f6427. http://dx.doi.org/10.1136/bmj.f6427

[54] Schell, C.O., Reilly, M., Rosling, H., Peterson, S. and Mia Ekström, A. (2007) Socioeconomic Determinants of Infant Mortality: A Worldwide Study of 152 Low-, Middle-, and High-Income Countries. Scandinavian Journal of Public Health, 35, 288-297. http://dx.doi.org/10.1080/14034940600979171

[55] Kuhn, L., Sinkala, M., Semrau, K., Kankasa, C., Kasonde, P., Mwiya, M., et al. (2010) Elevations in Mortality Asso- 
ciated with Weaning Persist into the Second Year of Life among Uninfected Children Born to HIV-Infected Mothers. Clinical Infectious Diseases, 50, 437-444. http://dx.doi.org/10.1086/649886

[56] Kafulafula, G., Hoover, D.R., Taha, T.E., Thigpen, M., Li, Q., Fowler, M.G., et al. (2010) Frequency of Gastroenteritis and Gastroenteritis-Associated Mortality with Early Weaning in HIV-1-Uninfected Children Born to HIV-Infected Women in Malawi. JAIDS Journal of Acquired Immune Deficiency Syndromes, 53, 6-13. http://dx.doi.org/10.1097/QAI.0b013e3181bd5a47

[57] Homsy, J., Moore, D., Barasa, A., Were, W., Likicho, C., Waiswa, B., et al. (2010) Breastfeeding, Mother-to-Child HIV Transmission, and Mortality among Infants Born to HIV-Infected Women on Highly Active Antiretroviral Therapy in Rural Uganda. JAIDS Journal of Acquired Immune Deficiency Syndromes, 53, 28-35. http://dx.doi.org/10.1097/QAI.0b013e3181bdf65a

[58] Landes, M., van Lettow, M., Chan, A.K., Mayuni, I., Schouten, E.J. and Bedell, R.A. (2012) Mortality and Health Outcomes of HIV-Exposed and Unexposed Children in a PMTCT Cohort in Malawi. PLoS ONE, 7, e47337. http://dx.doi.org/10.1371/journal.pone.0047337

[59] WHO (2013) Guideline: Updates on the Management of Severe Acute Malnutrition in Infants and Children. World Health Organization, Geneva.

[60] Irena, A.H., Mwambazi, M. and Mulenga, V. (2011) Diarrhea Is a Major Killer of Children with Severe Acute Malnutrition Admitted to Inpatient Set-Up in Lusaka, Zambia. Nutrition Journal, 10, 110. http://dx.doi.org/10.1186/1475-2891-10-110

[61] Mwiru, R.S., Spiegelman, D., Duggan, C., Seage, G.R., Semu, H., Chalamilla, G., Kisenge, R. and Fawzi, W.W. (2013) Nutritional Status and Other Baseline Predictors of Mortality among HIV-Infected Children Initiating Antiretroviral Therapy in Tanzania. Journal of the International Association of Providers of AIDS Care.

[62] Musoke, P.M. and Fergusson, P. (2011) Severe Malnutrition and Metabolic Complications of HIV-Infected Children in the Antiretroviral Era: Clinical Care and Management in Resource-Limited Settings. American Journal of Clinical Nutrition, 94, 1716S-1720S. http://dx.doi.org/10.3945/ajcn.111.018374

[63] Prendergast, A., Bwakura-Dangarembizi, M., Cook, A.D., Bakeera-Kitaka, S., Natukunda, E., Nahirya Ntege, P., et al. (2011) Hospitalization for Severe Malnutrition among HIV-Infected Children Starting Antiretroviral Therapy. AIDS, 25, 951-956. http://dx.doi.org/10.1097/QAD.0b013e328345e56b

[64] UNICEF (2013) HIV and Infant Feeding: The Facts. http://www.unicef.org/programme/breastfeeding/hiv.htm

[65] Harries, A.D., Nkhoma, W.A., Thompson, P.J., Nyangulu, D.S. and Wirima, J.J. (1988) Nutritional Status in Malawian Patients with Pulmonary Tuberculosis and Response to Chemotherapy. European Journal of Clinical Nutrition, 42, 445-450.

[66] Duggan, C., Manji, K.P., Kupka, R., Bosch, R.J., Aboud, S., Kisenge, R., Okuma, J. and Fawzi, W.W. (2012) Multiple Micronutrient Supplementation in Tanzanian Infants Born to HIV-Infected Mothers: A Randomized, Double-Blind, Placebo-Controlled Clinical Trial. American Journal of Clinical Nutrition, 96, 1437-1446. http://dx.doi.org/10.3945/ajcn.112.044263

\section{Abbreviations}

HIV: Human immunodeficiency syndrome

HEU: HIV exposed uninfected

AIDS: Acquired immunodeficiency syndrome

PMTCT: Mother-to-child prevention of HIV transmission

WHO: World health organization

SAM: Severe acute malnutrition

CD4: Cluster of differentiation 4

SD: Standard deviation 
Scientific Research Publishing (SCIRP) is one of the largest Open Access journal publishers. It is currently publishing more than 200 open access, online, peer-reviewed journals covering a wide range of academic disciplines. SCIRP serves the worldwide academic communities and contributes to the progress and application of science with its publication.

Other selected journals from SCIRP are listed as below. Submit your manuscript to us via either submit@scirp.org or Online Submission Portal.
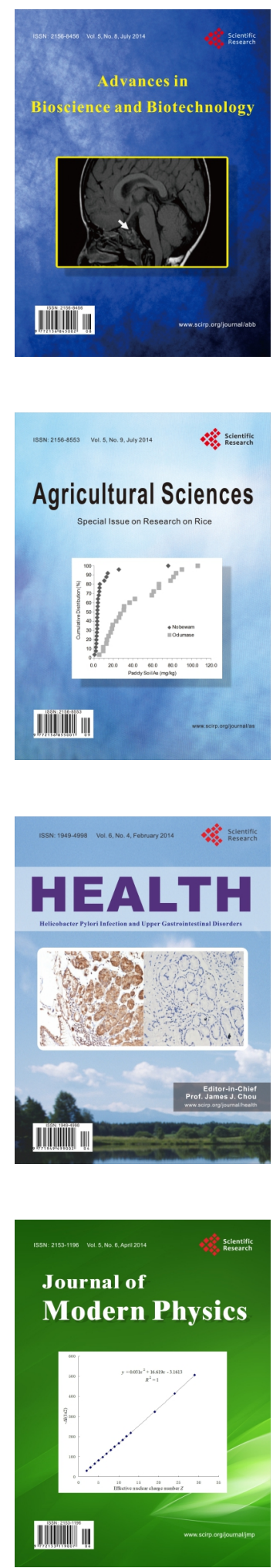
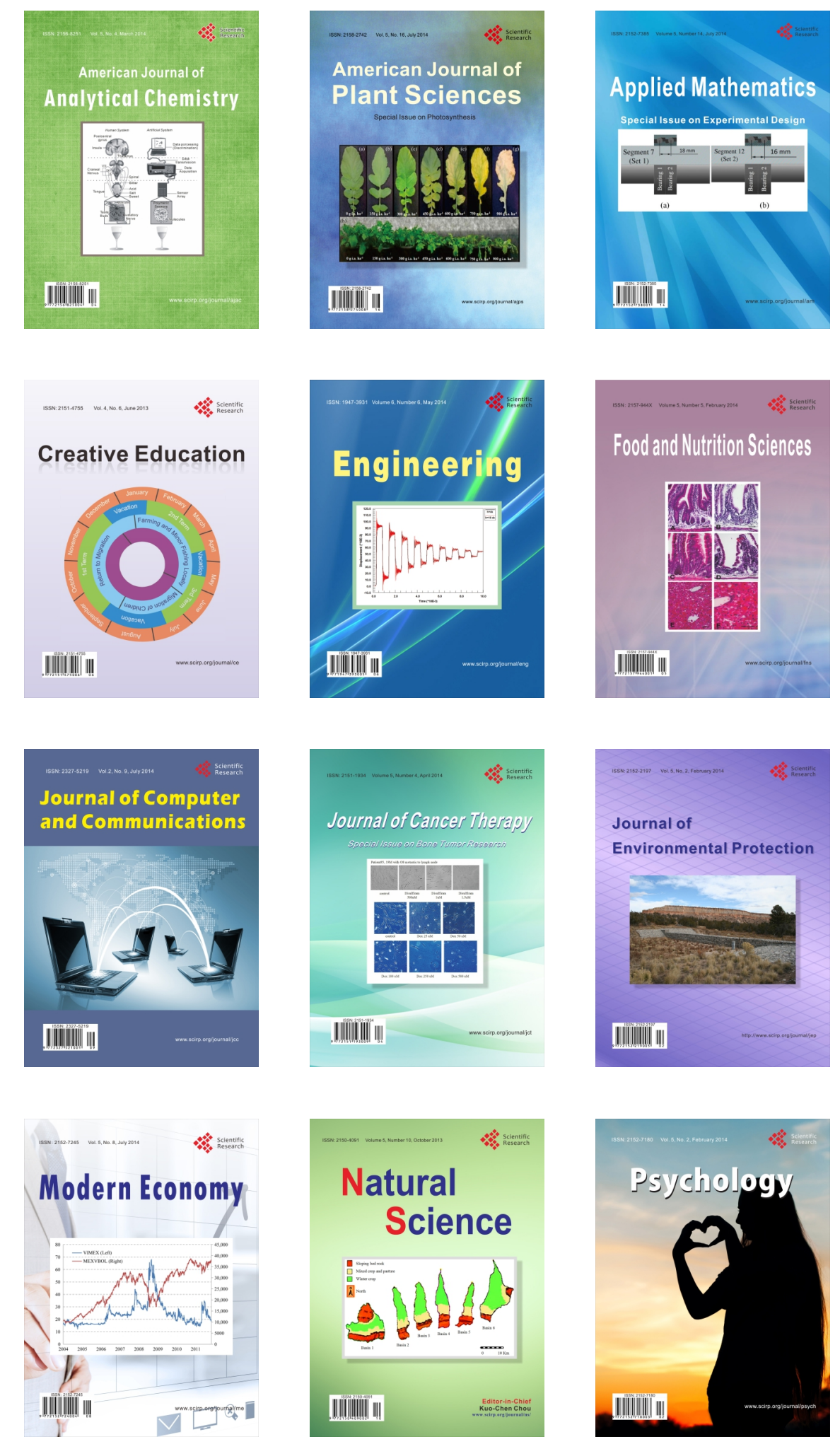